\title{
La problemática del VIH-SIDA entre los pobladores del casco urbano de Laguna de Perlas, RAAS, 2007 -2008.[23]
}

\author{
Ana Lucía Chow Taleno ${ }^{[24]}$ \\ Tenia Teresa Taylor Hodgson ${ }^{[25]}$ \\ Jesús Salgado ${ }^{[26]}$
}

\section{Resumen}

Esta investigación aborda las percepciones socioculturales de la población del casco urbano de la comunidad de Laguna de Perlas relacionadas a la problemática del VIH y el SIDA. La población está consciente que el SIDA no tiene cura; pero, tampoco existe confianza en las instancias estatales (Centro de Salud - Hospital de Bluefields) para realizarse la prueba del VIH debido a la falta de confidencialidad según los entrevistados.

Para mejorar resultados en la prevención de la epidemia se valora la ejecución de campañas educativas con la niñez, jóvenes y adultos. La cultura y la espiritualidad juegan un papel determinante en la prevención; no obstante, se debe desechar las creencias relacionadas a la percepción del castigo divino o el pecado porque induce a la exclusión social de los infectados por el SIDA.

Algunas características asociadas a la infección se expresan en la inequidad de género, por ejemplo con la sumisión de la mujer, a quien se asocia en algunos casos con relación al uso de condón como sinónimo de infidelidad, desconfianza que sale a flote a lo interno de las parejas.

Aunque los índices del SIDA en Laguna de Perlas son bajos según Acción Médica Cristiana (AMC), la población valora que no está preparada para enfrentar el avance de la pandemia, y reconocen que al constituirse el SIDA en un problema social, requiere la integración organizacional que asegure un circulo solidario en los portadores y aporte mayor confianza para hacerse la prueba para adquirir compromisos colectivos de responsabilidad.

\footnotetext{
[23] Monografía realizada con financiamiento de la fundación FORD con el proyecto Pathway II"Support to Graduation Research Projects of Indigenous and Afro Desendant Students in URACCAN".

[24] Licenciada en Sociología con Mención en Autonomía, Univ. URACCAN.

[25] Licenciada en Sociología con Mención en Autonomía, URACCAN.

[26] Profesor de la URACCAN, tutor de la investigación.
}

98 | CIENCIA E INTERCULTURALIDAD, Edición No 3, Diciembre 2008 
Palabras Claves: VIH-SIDA, Laguna de Perlas, comportamiento poblacional.

\section{Introducción}

La pandemia del Síndrome de Inmunodeficiencia Adquirida -SIDA-, es una enfermedad que afecta a los humanos infectados por el Virus de Inmunodeficiencia Humana (VIH), y atañe no sólo un problema de salud, porque no daña solo al cuerpo sino a toda la persona en todos sus ámbitos y contextos, esto implica sus relaciones interpersonales y su vida social.

Según la Organización Mundial de la Salud, hasta finales del año 2007 se reportan más de 28 millones de personas fallecidas en todo el mundo y en nuestra región hasta el mes de noviembre del 2008 se registraron más de 140 casos de acuerdo al Sistemas Local de Atención Integral en Salud (SILAIS) - RAAS, estos datos nos confirman que el VIH y el SIDA se ha transformado en un grave problema social.

El presente estudio permite describir y analizar el comportamiento de la población del casco urbano de Laguna de Perlas en relación al abordaje del VIH y el SIDA.

El Municipio de Laguna de Perlas, tiene una extensión territorial de 3,876 Km y una población de 12,552 habitantes distribuida en 12 comunidades, (VIII Censo Nacional de Población 2005 y de la Encuesta Nicaragüense de Demografía y Salud 2006/07) está ubicada a 45 km al Norte de la Ciudad de Bluefields, cabecera de Región Autónoma del Atlántico Sur (RAAS).

Laguna de Perlas es junto a Bluefields y Corns Island los referentes representativos de los afrodescendientes del Caribe nicaragüense, históricamente considerada la segunda capital del reino de La Mosquitia, fue conocida durante la colonización Inglesa como Cheerbars Bank y en 1831 como Magdala, puesto que la primera iglesia en la localidad se llamaba Magdala Moravian Church.

Bíblicamente Magdala es referencia a un pueblo ubicado a orillas del mar de Galilea, cerca de Tiberias y Hammath, por tal razón la comunidad decidió utilizar este nombre para mayor connotación. (The new westminster:Dictionary of the Bible, Edited by Henry Zinder Gehman, Publisher in 1944, provided by Rev. Juan Ordoñez).

"Laguna de Perlas recibe su actual nombre en 1860 con la llegada de los españoles, pero se cree que la comunidad adquirió este nombre debido a la cultura de sus antepasados, que comían grandes cantidades de ostiones y encontraban perlas en su 
interior. En 1882 fue favorecida con la electricidad y entre 1950 a 1964 se desarrolla la Educación Primaria impartida en idioma inglés y el pago de los docentes era asumido por la iglesia Morava. En el 2007 y con el apoyo de la embajada del Japón se construyó una trocha de 18 kilómetros (carretera terrestre que une al municipio de Kukra Hill, favoreciendo su desarrollo comercial). Hace 5 años la industria pesquera en esta localidad fue cerrada, motivo por el cual actualmente la población sobrevive con remesas familiares procedentes del exterior, especialmente de "embarcados" o "shipout" que trabajan en los barcos turísticos internacionales. En la comunidad conviven garífunas, mestizos, creoles y miskitus" (Entrevista al Sr. Wesley Williams).

En este estudio se analiza la visión, actitudes y comportamiento de la comunidad para enfrentar este problema y encontrar respuestas conjuntas encaminadas a reducir los daños potenciales.

Asimismo, se tuvo la participación de la población, organizaciones y representaciones religiosas que trabajan con el programa de prevención y lucha contra el SIDA en la comunidad, actores que coinciden que la epidemia del VIH y el SIDA.

\section{Revisión de literatura}

En la revisión bibliográfica no se encontraron referencias locales relacionadas al abordaje sociocultural de la pandemia, pero son valorables algunos estudios que abordan la perspectiva de la salud comunitaria en las Regiones Autónomas: La salud en la Costa Caribe, la experiencia del modelo de salud intercultural en la RAAN $1984-2000$ (Cuninngham, Myrna) y La experiencia de la salud intercultural como herramienta para la equidad en las Regiones Autónomas de Nicaragua.

El SIDA como problema de salud pública requiere ser abordado desde un enfoque integral de acorde a las pautas sociales, se necesita cambiar el discurso, nos complementamos con el Dr. Francisco Maglio en cuanto para enfrentar el SIDA, es necesario un nuevo enfoque.

SIDA un enfoque integral. (Pedro Cahn pág. 213). El problema de exclusión social se acrecienta aún más por las diferencias culturales, encontramos en este mismo autor que la ausencia de una perspectiva integral e intercultural impide una comprensión global del SIDA.

La sociología es una ciencia social que se dedica al estudio de la sociedad, los fenómenos, evolución y transformación que en ella ocurren; asimismo, las acciones sociales 
entre individuos y grupos, esto incluye sus estructuras creadas como organizaciones e instituciones que la conforman, es decir las relaciones humanas de forma integral.

En el enfoque sociocultural se intretan los aspectos de la vida de una comunidad o individuo para comprender aspectos que van desde su cosmovisión, historia, tradiciones, concepciones, valores y creencias que determinan e influyen en las normas de comportamiento y sus formas de organización.

De acuerdo a Nereida Rojo Pérez (OMS), el enfoque sociocultural en el tema el VIH- tiene dos líneas de acción fundamentales:

- Entender el fundamento de los aspectos culturales, antropológicos y sociológicos del comportamiento humano frente a la epidemia.

- Modelar un sistema de acciones en el área de la promoción de la salud y la prevención de la enfermedad, donde se asuma el universo cultural de las poblaciones destinatarias.

En el abordaje sociocultural se utilizan diferentes términos, por ejemplo: algunos autores señalan usar el término multiculturalidad que "se refiere al hecho de que muchos grupos o individuos pertenecientes a diferentes culturas vivan juntos en la misma sociedad, se interrelacionan, se enriquecen mutuamente y son conscientes de su interdependencia". (Teresa Aguado, profesora titular del Departamento de Métodos de Investigación y Diagnóstico en Educación de la Universidad Nacional de Educación a Distancia -UNED-).

En este sentido nos planteamos entender el abordaje socio cultural como las formas de ver, entender e interactuar en el entorno desde la perspectiva cultural de cada comunidad, apoyándonos en conceptos: cosmovisión, apropiación y creencias.

Cosmovisión: Es el conjunto de opiniones y creencias que conforman la imagen o concepto general del mundo que tiene una persona, época o cultura, a partir del cual interpreta su propia naturaleza y todo lo existente. Para efectos del presente estudio es entendida como las percepciones que tiene la comunidad de Laguna de Perlas desde sus expresiones organizativas para abordar el VIH-SIDA.

Tradición: La constituyen aquellos contenidos que heredamos del pasado, y que conforma la "herencia histórica" de acuerdo con Pior Sztompka (sociología del cambio social). 
Apropiación: Entenderemos el concepto de apropiación como las prácticas propias del individuo y su comunidad, en este caso específico en el manejo de información relacionadas al VIH y el SIDA.

Creencias: Son las ideas compartidas acerca de cómo opera el mundo, pueden ser sumarias e interpretaciones del pasado que pueden tener fundamentos en el sentido común, sabiduría popular, religión o ciencia o en alguna combinación de estos.

\section{Materiales y métodos}

El proceso metodológico se desarrolló en las siguientes cinco etapas:

1. Identificación del problema, elaboración del perfil y redacción del protocolo de investigación.

2. Recopilación y revisión de información básica referente a la problemática en la región.

3. Presentación del estudio a organizaciones locales y líderes de la comunidad, exploración, reconocimiento y familiarización con el territorio, difusión de la iniciativa y confirmación de participantes, locales y horarios.

4. Aplicación de instrumentos:

a. Entrevistas a profundidad con funcionarios de instituciones y organizaciones locales que desarrollan programas relacionados a la prevención del VIH y el SIDA, establecidos en la ciudad de Bluefields y Laguna de Perlas.

b. Eentrevistas informales con pobladores de la comunidad.

c. Sondeos de opinión a jóvenes y adultos que se encontraban en lugares públicos como tiendas, muelle municipal, calles de la comunidad.

d. Aplicación de guía de observación participante a líderes de la comunidad.

e. Grupo focal con jóvenes, pastores de la comunidad y representantes de organizaciones locales.

5. Devolución de los resultados de la investigación a la comunidad.

$\mathrm{Al}$ inicio de esta investigación adquirimos documentos bibliográficos de la organización nacional Servicios Integrales para la mujer (SI MUJER), Comisión Regional de lucha contra el SIDA, CORESIDA - Horizont3000, y la Asociación Centro Regional de Información y Consejería de lucha contra el sida -ACRIC-, Departamento de Epidemiología del SILAIS -Bluefields, Asociación Campaña Costeña contra el SIDA, 
entre otras organizaciones con sede en la ciudad de Bluefields y con programas ejecutados en la comunidad en estudio.

Entre las entrevistas de profundidad se realizaron con el Dr. Edwin Flores, director del centro de salud del Municipio de Laguna de Perlas; Licda. Julieth Antonio, Directora de Acción Médica Cristiana; Sra. Marcia de Acosta, representante del Centro de Derechos Humanos Ciudadanos y Autonómicos CEDEHCA; la Sra. Ireen Cuthberth de la Comisión Nacional de Lucha contra el SIDA (CONASIDA); el señor Wesley Williams, representante de la Oficina de Mediación Comunitaria de la localidad; Randall Cayasso, Hemrick Rigby y Juan Ordóñez, Pastores de las diferentes iglesias establecidas en esta comunidad; profesora Yanina Cuthberth, sub-directora del Instituto de secundaria "Las Perlas"; los señores Teodoro Hebberth y Alejandro Estrada, curanderos de la zona; asimismo, sondeos al azar entre estudiantes y pobladores de esta comunidad.

Aplicación de cuatro grupos focales: uno con estudiantes del Instituto de Secundaria "Las Perlas", un segundo con jóvenes de la comunidad, un tercero con funcionarios de instituciones, y un último entre pastores y pobladores de la localidad.

Entre los grupos focales, sondeos y entrevistas participaron un total de 63 personas, un comportamiento común observado en la mayoría de los entrevistados fue la evasión a preguntas y la sorpresa.

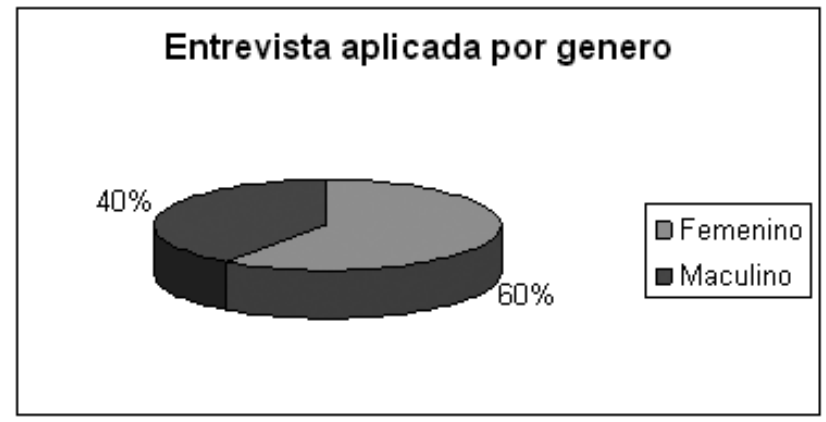

GRÁFICA No. 1: Entrevistas aplicadas por género. 


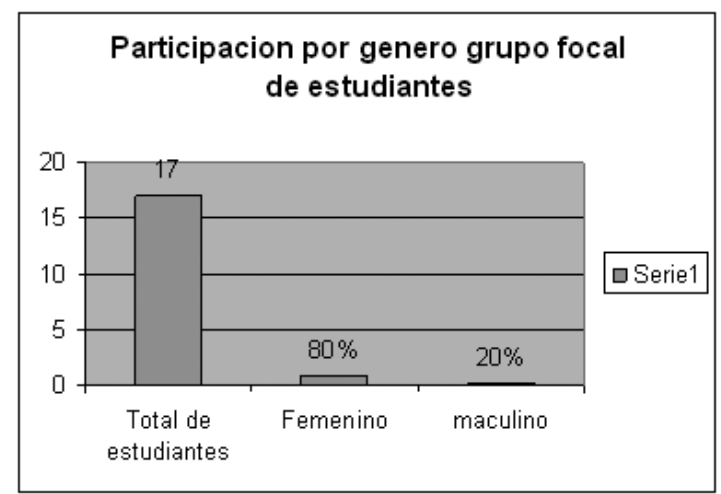

GRÁFICA No. 2: Participación de estudiantes del instituto las Perlas en los grupos focales por género.

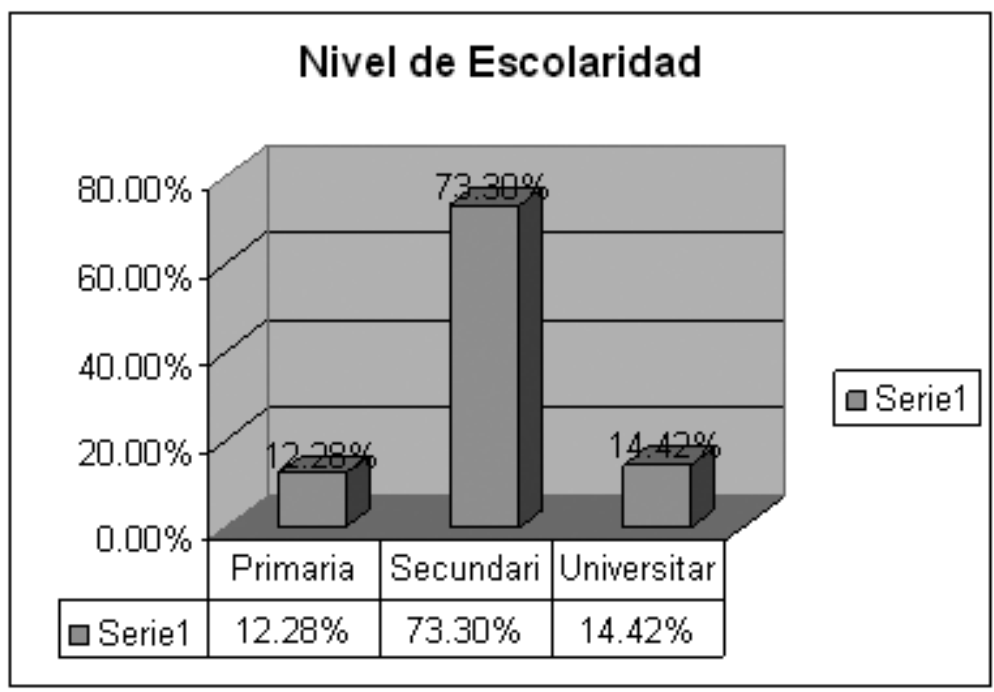

GRÁFICA No. 6: Participantes por nivel de escolaridad. 


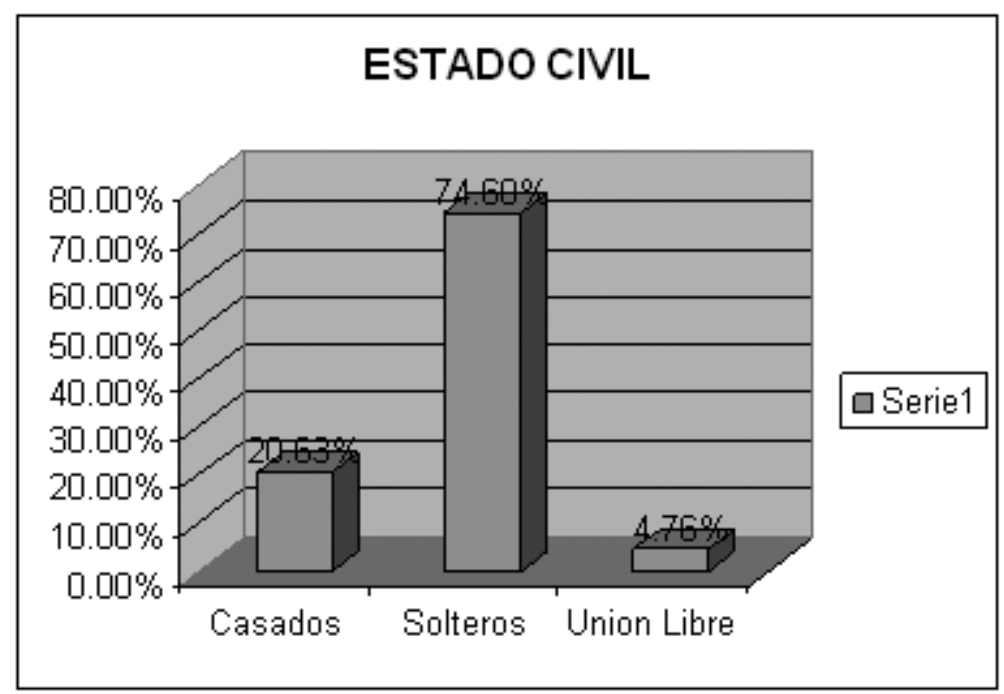

GRÁFICA No. 7: Participantes por estado civil.

\section{Resultados y discusión}

\section{Percepciones relacionadas a la problemática del VIH y el SIDA}

La población del casco urbano en la comunidad de Laguna de Perlas posee una visión del SIDA como un problema social, porque reconoce que los pacientes portadores de esta enfermedad modifican sus ambientes, entorno y relaciones sociales que van más allá de la vida privada del individuo, reconocen que ser portador del VIH o contraer el SIDA implica una serie de transformaciones socioculturales en la vida del individuo y su comunidad, sujetas a una serie de tabús y creencias que pueden llevar a un portador a ser excluido socialmente.

Otra percepción es la asociación de la enfermedad con lo foráneo o exterior a la comunidad, muchos de los jóvenes encuestados en el sondeo creen que la enfermedad es para ciudades grandes, que la transmiten los extranjeros que visitan la comunidad, y casi similar piensan algunos adultos, pues creen que esta enfermedad la traen quienes trabajan en el exterior del país. Un anciano dijo que él pensaba que esta enfermedad se adquiría en Honduras, en relación a la migración de algunos laguneños a ese país; incluso una joven de secundaria manifestó que es posible que esta enfermedad la traigan los mestizos del Pacifico de Nicaragua. 
Algunas de estas interpretaciones pueden tener su incidencia debido a que Laguna de Perlas era una comunidad de difícil acceso, únicamente marítima, con pocas conexiones al exterior y la enfermedad se asocia con personas foráneas a la comunidad que reconocen como extraños, extranjero y mestizos del interior del país y en últimos casos los comunitarios con nexos en el exterior.

La percepción del VIH y SIDA es similar a la creencia colectiva en Bluefields quienes creen que el SIDA está presente por los trabajadores de barcos turísticos del exterior y que operan en líneas como la Royal Caribbean; muchos padres de familia de Laguna de Perlas señalan que la falta de empleo promueve procesos de migración en la zona y que incide directamente para que los jóvenes tomen la decisión de emigrar (embarcados) y creen que esto ha contribuido para que el nivel de infectados con el virus haya aumentado.

Económicamente Laguna de Perlas sobrevive de la pesca artesanal que ha decaído en los últimos 10 años. No obstante, esta comunidad ofrece un potencial ecoturístico (Revista La gente INTUR, octubre, 28.2008) para promover el turismo rural comunitario, agroturismo y el turismo de aventura de acuerdo a los intereses del gobierno regional y central, en este sentido la comunidad logró habilitar la antigua trocha de 18 kilómetros entre Kukra Hill y Laguna de Perlas; pero algunos líderes de la comunidad temen que la enfermedad prolifere con los mestizos que están llegando a la zona a promover el comercio (El Nuevo Diario, Aceleran tramo Kukra Hill-Laguna de Perlas, Viernes 13 de octubre 2006).

Acción Medica Cristiana (AMC) considera que la crisis económica es un factor importante en la tasa de la proliferación de esta enfermedad y que este fenómeno está ligado a los estados de pobreza de grandes sectores de la población, porque se han modificado las actividades económicas, cuando muchos padres de familia han tenido que buscar mejores oportunidades de empleos fuera de la comunidad. Señala esta organización que el municipio de Laguna de Perlas tiene un índice bajo en la propagación de esta epidemia que todavía se encuentra en su etapa temprana; empero, se debe mantener un control sobre la epidemia, señala el diagnóstico que la presencia de infecciones de transmisión sexual son una puerta al VIH (Entrevista Dr. Samuel Amador, Gerente Regional Acción Medica Cristiana-Bluefields).

Jóvenes y adultos también coinciden en la conducta, comportamiento y prácticas libertinas entre los jóvenes quienes no miden las consecuencias de sus actos, adoptan hábitos como el abuso en el consumo de licor y cigarrillos, y las prácticas sexuales inseguras a temprana edad, en este sentido Acción Medica Cristiana (Nicaragua, 2008) 
señala que las investigaciones realizadas sobre esta problemática deducen que los adolescentes están iniciando y manteniendo relaciones sexuales a temprana edad.

Las percepciones relacionada al género es diverso y tendencioso, como es de esperarse existe la prevalecía del machismo y la asociación del género masculino con la fortaleza y protección, esta apreciación es únicamente en los jóvenes pues los adultos consultados no hacen distinciones por género.

\section{Poca confianza en las instituciones}

El abordaje y las apreciaciones de la comunidad también está en un nivel de desconfianza hacia las organizaciones gubernamentales, en este caso el MINSA representado en el centro de salud de la comunidad, pues no se observó materiales públicos, radiales o de otra índole para lograr la concientización, se encontró pequeños volantes informativos en la parte lateral del centro y no se suministró ninguna información solicitada a esta institución, se usaron tácticas dilatorias para evitar suministrar datos generales. La población siente que sus derechos a la privacidad son violentados como lo cita la Ley 238, el Arto.7 (Ley de promoción y defensa de los derechos humanos ante el SIDA. Aprobado el 20 de Octubre de 1999 Publicado en La Gaceta No.238 del 14 de Diciembre de 1999).

Inicialmente el objeto de esta ley es velar por el resguardo de la integridad de las personas que conviven con el VIH y el SIDA, brindar protección legal para las personas afectadas y promover la solidaridad social para evitar cualquier tipo de discriminaciones hacia las personas portadoras, pero en la comunidad si alguien es sospechoso de portar la enfermedad, es sinónimo de exclusión social y una serie de connotaciones que perjudican aun más el estado de la persona, señalan los entrevistados que ese temor se siente además en las instancias médicas en Bluefields.

A esto se suma que los servicios de salud en la región, específicamente en Laguna de Perlas no son apropiados para brindar una atención especializada a personas que conviven con el Síndrome de Inmunodeficiencia Adquirida (SIDA), ya que no cuentan con personal calificado, local adecuado y los recursos necesarios para ofrecer el tratamiento de retro virales a los pacientes.

El temor al rechazo y las implicancias de ser señalado de portar el VIH o el SIDA es sinónimo de exclusión social, es una repuesta ante la pandemia en la región y los bajos resultados de la población para hacerse la prueba, barrera que se estigmatiza aun en una población culturalmente diferenciada, porque además de enfrentar las implicaciones sociales de la enfermedad tiene que enfrentar asuntos de idioma, cultura, 
formas de ver su mundo y otras limitaciones que debe afrontar el sistema de salud del país para atender las prioridades de estas poblaciones que demandan un modelo de salud que responda a su contexto y necesidades etno-geográficas.

Mujeres y hombres coinciden que el SIDA es uno de los problemas públicos que debe ser atendido por la atención primaria del Ministerio de Salud y señalaron la responsabilidad de los gobiernos: central, regional y municipal para desarrollar las principales acciones de prevención y tratamiento a la enfermedad.

Los comunitarios citados plantean que la organización no gubernamental Acción Médica Cristiana ha implementado estrategias de información y prevención en la comunidad y que esta organización en coordinación con iglesias y otras expresiones organizadas de la comunidad deben seguir desarrollando su trabajo con financiamiento del gobiernos central, regional y municipal. La comunidad también valora que el trabajo realizado por AMC depende exclusivamente de la cooperación internacional.

\section{El abordaje en la medicina tradicional}

El estudio también consultó las expectativas, relaciones de los médicos reconocidos tradicionalmente en la comunidad para reflexionar en torno a la atención de la pandemia.

Algunos curanderos manifestaron su confianza en la medicina tradicional y aunque reconocen que no manejan con profundidad el desarrollo de la epidemia, argumentan que se sienten capacitados para tratar a personas afectadas. Cuando se trata de alguna situación que molesta al paciente, casi siempre existe algo que ofrecer para aminorar dolores o ataques físicos al cuerpo, coinciden que quizás han tratado con pacientes portadores, pero que los pacientes hacen menciones físicas y estás son tratadas como síntomas de otra enfermedad; sin embargo, también reconocen que han orientado y tratado a portadores de la pandemia que no optaron por seguir el modelo que ofrece la salud pública, MINSA.

Los médicos tradicionales miskitu, kriol y garífuna manifiestan que aprecian y valoran los conocimientos heredados por sus ancestros y que estos conocimientos se han fortalecido en cada generación familiar.

Manifiestan que el gobierno se ha comportado demasiado lento para implementar una ley aprobada que encamine la integración de la medicina tradicional o natural con el Sistema Regional de Salud y justifican que personas de las diferentes comunidades recurren siempre en busca de la medicina natural. 
Aseveran que las instituciones y organizaciones que trabajan la prevención de la pandemia los tienen excluidos de sus programas, por lo tanto no existe ninguna relación entre la institución y curanderos; uno de ellos mencionó que gracias al Instituto de Medicina Tradicional de la Universidad URACCAN de Bluefields, ha participado en foros académicos y se ha capacitado para abordar el problema, también reconoce que el resto de médicos deben ser incorporados y trabajar en coordinación con las organizaciones de la comunidad, porque sienten el compromiso de ayudar a personas que conviven con el VIH y el SIDA.

\section{Limitaciones en la apropiación de la información entre los pobladores y enfoque liberal en los mensajes de las campañas de prevención}

Cuando se reflexionó con una adolescente promotora que estaba en estado de embarazo, argumentaba que maneja la información básica de la prevención y que están informados sobre la problemática, dejando entre dicho que los jóvenes están inmunes; incluso algunos adultos entrevistados señalan que en los mismos grupos de promotoría e información sobre la enfermedad, han salido otras jóvenes embarazadas y que todo indica que lo que realmente existe es una campaña de promover las relaciones sexuales, porque insisten en el uso del condón.

En este sentido los pastores dicen que la iglesia promueve siempre la fidelidad entre las parejas, el matrimonio, y la abstinencia; igualmente los profesores del Instituto Las Perlas, plantean que estas campañas deben realizarse con todos los estudiantes de todas las edades, y que el Ministerio de Educación debe incluir el abordaje de la temática en los programas de enseñanza, insistiendo que el enfoque de este contenido debe de ser científico y educativo sin prejuicio social.

Los estudiantes, jóvenes y adultos encuestados coinciden que las campañas contra el SIDA están enfocadas en el uso de preservativos, específicamente del condón y reflexionan que deben ajustarse su contenido y debatir más a fondo las formas, métodos que sensibilicen la población.

El fenómeno de una campaña por la libertad sexual nos induce de manera indirecta a tener las situaciones anteriores, por tal razón se debe analizar las campañas de difusión e información para prevenir la enfermedad, las temáticas y sus enfoques deben revisarse y ajustarse, además se debe medir el impacto de las mismas en los jóvenes la población en general.

Algunos pobladores adultos y jóvenes consideran innecesario la adquisición de nuevos conocimientos relacionados a la protección y prevención de la pandemia, 
sostienen en mantener sus costumbres y reaccionan como ante otra enfermedad que aducen " natural" y no consideran necesario la protección.

Los jóvenes que han logrado adquirir información mantienen la idea de que este virus únicamente se transmite por el acto sexual y confían que la utilización del condón les asegura protección. En el caso de las parejas adultas conservan los comportamientos tradicionales, algunos señalan que el uso del condón en la pareja induce a la sospecha, la desconfianza y despierta problemas conyugales de infidelidad, a esto se asocia la prevalencia de un connotado machismo que aún persiste.

\section{Analizar las creencias tradicionales y espirituales que intervienen para el acceso al servicio médico entre los pobladores}

Las creencias tradicionales son aquellas que la comunidad conserva y se resiste a que se extingan, y están asociadas a su forma de ver y entender su entorno, que es transmitido generacionalmente.

Representantes de organizaciones no gubernamentales señalan que muchos jóvenes tienen acceso a la información ilimitada a través de los medios de difusión que imponen modas y nuevos roles que promueven el consumos de tabaco, licores y cervezas que son mezcladas con estilos de vida libertinos o desordenados que incluyen relaciones sexuales tempranas y sin protección.

Jóvenes que abandonan sus estudios o adultos que emigran a otros lugares en busca de empleo o estudio y que se exponen a prácticas sexuales libres y que al retornar a la comunidad también exponen a la población.

Entre las creencias de la población se identificaron las siguientes ideas: El SIDA surgió en Honduras, surgió en Estados Unidos en un laboratorio de experimento con animales, el SIDA se transmite en las grandes ciudades, la transmiten los extranjeros, la portan los mestizos que vienen a la comunidad.

La religión es en parte un sistema de creencias acerca de lo que es sagrado (Donald Light - Sociología, Quinta edición, Pág.: 524.) En este sentido las creencias religiosas observadas en la población de Laguna de Perlas, están asociadas al castigo divino a causa del pecado y la infidelidad entre las parejas que no conviven bajo la figura del matrimonio cristiano, es en este contexto que los adultos aducen el no uso del condón por las connotaciones de inseguridad y desconfianza entre la pareja. 
Sin embargo, la iglesia que está agrupada en el Concejo Ecuménico de la Comunidad es una organización aliada de Acción Medica Cristiana para transmitir el mensaje de prevención en los feligreses, y el contenido de estos mensajes hacen énfasis en la integración y construcción de la familia, la abstinencia de las relaciones sexuales si no están en matrimonio, la iglesia juega un rol determinante en la protección de la familia y orienta a sus feligreses a conservar estados armónicos y tradicionales en la comunidad.

\section{Conclusiones}

La sociología percibe el SIDA como un fenómeno social y como una enfermedad, la respuesta además de médica debe enfocarse hacia los valores sociales como la solidaridad, el apoyo mutuo, comportamiento afectivo de la familia y la comunidad frente a las personas portadoras del VIH y el SIDA.

Existe la percepción que el SIDA es un problema de la comunidad donde aparentemente predomina la cultura afrodescendiente de la etnia kriol, los grupos étnicos miskitus, garífunas y mestizos quienes han adoptado de alguna manera la lengua kriol que tiene uso oficial en sus actos públicos, la escuela y la iglesia, aunque compite con el español, son también utilizados el miskitu en el seno del hogar y la comunidad.

Esta multiculturalidad lingüística tiene tendencia a mestizarse a consecuencia de la apertura de la comunicación terrestre y la afluencia de familias mestizas en la zona: comerciantes en el interior de la comunidad y familias campesinas en sus alrededores o en la zona de Wawashang, a esto se asocia la construcción de la calle principal que modifica el paisaje natural de una comunidad que se apresura a impulsar el desarrollo con la construcción de las vías de comunicación, la incorporación a la red nacional de distribución energética y la instalación del servicio de agua potable.

La población de la comunidad en su mayoría están conscientes que el SIDA es un problema social porque afecta más allá del entorno privado. El SIDA no tiene cura y los afectados necesitan apoyo solidario para enfrentar la epidemia. La comunidad no está preparada para enfrentar un crecimiento acelerado de esta pandemia y no existe confianza en las instancias estatales (Centro de Salud - Hospital de Bluefields) para hacerse la prueba, por la falta de confidencialidad, el temor al rechazo, exclusión social y caer en un estado de depresión.

Esta exclusión amplía las dimensiones socioculturales, el hecho de ser pobre, mujer, indígena, portadora, tiene serias implicaciones de exclusión social por razones 
de economía, género y cultura, acción que puede asociarse a la desconfianza para hacerse la prueba o dar seguimiento a los retrovirales una vez que se diagnostica. Similar situación es para un afrodescendiente, miskitu, garífuna, mestizo, ulwa, quienes además de superar la barrera de exclusión que implica portar el virus, tienen que sobrepasar sus barreras socioculturales

Las instituciones que están trabajando estrategias de prevención de la pandemia del SIDA, han enfocado su campaña en la prevención y se ha condonizado el contenido de los mensajes, sin medir impactos sustanciosos y cuyas consecuencias se observan en el aumento de la pandemia en la región.

No existe un abordaje integral de la pandemia, ni equipos ni recursos necesarios para enfrentarla, se requiere la conformación de equipos multidisciplinarios integrado por personal médico especializado: psicólogo, sociólogo, antropólogo y médico tradicional de la comunidad para responder a las necesidades de la comunidad. A esto se suma que la región no cuenta aún con un modelo de salud regional que promueva la articulación de nuestros médicos naturales con la medicina occidental.

\section{Lista de referencias}

Fernández, Oscar (1989). Sociología, Teoría y Métodos.

Light, Donald (1991) Sociología, Quinta Edición.

Morales Navarro, Julián (1988). Introducción a la Sociología.

Rojo Pérez, Nereida (2006). Enfoque sociocultural en la prevención del VIH y el SIDA, Taller Internacional de Centros Colaboradores OMS e Instituciones de Excelencia Científica, Cuba.

Simmel, Georg (1986) Estudio Sobre las Formas de Socialización. Sociología 2.

Tenorio Bellanger, Ligia (1999). Para Vivir el amor sin enfermedades de Transmisión Sexual, Programa de Adolescentes y Jóvenes - SI Mujer. Un enfoque integral - PSIDA.

Centro de Estudios y Promoción Social (sf). Impacto de la Epidemia del VIH/SIDA. Una aproximación no cuantitativa de su influencia. Centro de Estudios y Promoción Social -CEPS. 
CIDCA (2005). Aportes al modelo de Salud Regional de la Costa Caribe. Revista del Caribe Nicaragüense, WANI No.43, Octubre - Diciembre 2005.

CONISIDA (2006). Plan Estratégico Nacional de ITS, VIH y Sida en Nicaragua 2006-2010. Managua Nicaragua. 84p.

El Nuevo Diario (2006). Aceleran tramo Kukra Hill-Laguna de Perlas. Viernes 13 de octubre 2006.

MINSA (1997). Plan Estratégico Nacional de Lucha Contra las ETS/VIH/SIDA.

Movimiento Autónomo de Mujeres de Nicaragua (2005). Agenda de Salud Integral de las Mujeres,.Managua Nicaragua. 48p.

Morata Goetz,J.P. \& Le Compte,M.D.(1988). Etnografía y diseño cualitativo en investigación educativa. Madrid.

ONUSIDA (2002-2003) Estigma y discriminación, campaña Mundial contra el SIDA.

ONUSIDA (1997).La lactancia Materna y el VIH-SIDA, Campaña Mundial Contra el SIDA.

\section{Tomado de la dirección electrónica:}

Acción Médica Cristiana. Territorio_laguna_perlas. visitado el 16 de junio 2008. Disponible en www.amc.org.ni/amc/ .

Aguado, Teresa en Gil Jaurena, Inés. La interculturalidad. Artículo publicado en www. pedagogía. com).

Editorial Jurídica (2001). Constitución Política de la República de Nicaragua. Editorial Jurídica. Managua, Nicaragua. 112 p. 
Proyecto fondo mundial (2006). Nicaragua, compromiso y acción ante el SIDA, tuberculosis y malaria. Managua Nicaragua. , visitado el 16 de junio 2008. http://www.mcp.org.ni/mcp/

wikipedia. Cosmovisión. Visitado el 16 de junio 2008. Disponible en http:// es.wikipedia.org/wiki/Cosmovision.

\section{Personas entrevistadas}

Sr. Alejandro Estrada, Curandero-Laguna de Perlas.2008.

Enfermera Dania Jarquín, Departamento Epidemiología, SILAIS-Bluefields, 2008.

Licda. Donna Hamond, Acción Médica Cristiana-Laguna de Perlas.2008.

Sra. Ireen Cuthberth, CONASIDA-Laguna de Perlas.2008.

Licda. Julieth Antonio, Directora Acción Médica Cristiana-Laguna de Perlas.2008.

Doctor Samuel Amador, Director Acción Medica Cristiana-Bluefields, 2008.

Sr. Teodoro Hebberth, Curandero-Laguna de Perlas.2008.

Sr. Wesley Williams, Responsable Oficina Mediación Comunitaria-Laguna de Perlas. 2008. 